Bibliotecas. Vol 36, № 2, enero - junio, 2018. EISSN: 1659-3286

URL: http://www.revistas.una.ac.cr/index.php/bibliotecas/index

DOI: http://dx.doi.org/10.15359/rb.36-2.2

Licencia: Creative Commons (BY-NC-SA) 4.0 Internacional

\title{
Biblioteca Electrónica Scriptorium: Una contribución a la investigación y la docencia de la filosofía, las letras, la Identidad y la cultura
}

Library Electronic Scriptorium: A Contribution to the Research and Teaching of Philosophy, Letters, Identity and Culture

\author{
Aracelly Ugalde Víquez * \\ Margarita Rojas González ** \\ Carolina Gómez Fernández ***
}

Recibido: 06 de abril de 2016 Aceptado: 30 de junio de 2017 Corregido: 04 de octubre de 2017 Publicado: 11 de mayo de 2018

\section{Resumen}

El presente trabajo sintetiza el desarrollo de la actividad académica inscrita en el Sistema de información académica de la Universidad Nacional y describe la primera experiencia utilizada para la gestión y el control de la producción intelectual de la Facultad de Filosofía y Letras. Ello se realizó mediante la creación de una biblioteca electrónica y un repositorio con el propósito de identificar, conservar y preservar la memoria histórica que constituye esa producción académica en las áreas de conocimiento que se han estudiado y las que se estudian actualmente: filosofía, cultura, literatura, traducción, lingüística, bibliotecología, documentación, estudios de género, religión y sociedad, ética, derechos humanos, estudios centroamericanos y latinoamericanos.

Esa información no había sido registrada y no se encontraba disponible para su consulta en los acervos documentales en las colecciones de las bibliotecas; además, en su mayoría, estaba dispersa en los escritorios y en las casas de habitación, en estantes de los escritores, en su gran mayoría, en formato impreso; y otra, hasta en los recuerdos personales. 
Palabras clave: Gestión del conocimiento, Repositorios universitarios, Bibliotecas electrónicas, Patrimonio documental, Sistemas de información abiertos.

\section{Summary:}

The present work, which transcribes the project registered in the system of the National University academic formation, describes the first experiment used for management and control of the intellectual production of the Faculty of philosophy and letters, through the creation of a library and a repository for the purpose of identify, conserve and preserve the historical memory which is that academic work in the areas of knowledge have been studied and which are currently studying: philosophy, culture, literature, translation, Linguistics, librarianship, documentation, studies of gender, religion and society, ethics, human rights, Central American and Latin American studies.

That information had not been registered and was not available for viewing in the documentary collections in the collections of the libraries; In addition, was mostly scattered on desktops and in the houses of room, on shelves of the writers, mostly in printed format; and another, until on the memorabilia personal.

Keywords: Management Knowledge, University Repositories, Electronic Libraries, Documentary Heritage, Opens Information Systems.

\section{Descripción general}

La Facultad de Filosofía y Letras está integrada por las siguientes escuelas e institutos: Escuela de Bibliotecología, Documentación e Información, Escuela Ecuménica de Ciencias de la Religión, Escuela de Filosofía, Instituto de Estudios Latinoamericanos, Instituto de Estudios de la Mujer y Escuela de Literatura y Ciencias del Lenguaje. Las áreas del conocimiento que 
abarca la actividad docente e investigativa de estas unidades académicas son muy amplias: desde estudios de las lenguas, las literaturas, las culturas, las mujeres y las sociedades latinoamericanas hasta la filosofía, la teología, la bibliotecología y la documentación.

Scriptorium inició en 2002 primero con el nombre Colección Bibliográfica; en 2012 se cambió a Biblioteca electrónica. Para el 2010 había 48 publicaciones académicas; a inicios de 2012 se llegó a 873 publicaciones; en setiembre de 2012, 1.000 publicaciones; en 2014 eran 1.386 publicaciones y en enero de 2016 se alcanzaron 1.582 publicaciones originales a texto completo y acceso público, esto sin contar los números de la revista Repertorio Americano.

Con más de 12.000 publicaciones, una página en una red social y la colección en la base de datos del Sistema Documental de la Universidad Nacional (SIDUNA), Scriptorium cuenta con un sitio web www.scriptorium.una.ac.cr y posee el repositorio más grande de la UNA. El proyecto se planteó con los siguientes objetivos:

1. Constituir la memoria documental de la Facultad de Filosofía y Letras mediante la consolidación de la biblioteca digital y el repositorio Scriptorium.

2. Ofrecer servicios y productos en la biblioteca de Scriptorium por medio del aprovechamiento adecuado de las tecnologías de la información y comunicación.

3. Diseñar procesos de edición, normalización, interoperabilidad de sistemas y los instrumentos para el acceso y transparencia de la información en plataformas digitales.

\section{Marco contextual}

Scriptorium es la biblioteca digital de la Facultad de Filosofía y Letras de la Universidad Nacional, cuya misión es: "Ofrecer a la comunidad nacional e internacional el conocimiento resultado de la acción académica que se produce en la Facultad de Filosofía y Letras, en los campos de la reflexión filosófica, las manifestaciones socioculturales, la comunicación, por medio de la identificación, la descripción, la sistematización y la difusión de esa información". Su visión es "Consolidar el espacio idóneo para que la comunidad institucional y mundial 
tenga acceso a información sobre el quehacer académico de la Facultad de Filosofía y Letras".

Desde sus orígenes se ha caracterizado por la participación de un equipo interdisciplinario muy variado, por ejemplo inició con un historiador, una diaconisa y apoyo informático; actualmente el equipo de trabajo está constituido por dos filólogas, dos bibliotecólogos y una informática. El Cuadro 1 muestra los nombres del personal académico que ha participado en el proyecto.

\section{Cuadro 1}

Personal participante en Scriptorium y sus funciones

\begin{tabular}{|l|c|}
\hline Nombre completo de los participantes & Tipo de participación \\
\hline Ana Lía Calderón & Responsable, diaconisa \\
\hline Lucía Chacón Alvarado & Responsable, bibliotecóloga \\
\hline Margarita Rojas González & Responsable, semióloga \\
\hline Freddy Oviedo González & Informático \\
\hline Carolina Gómez Fernández & Informática \\
\hline Mauricio Moreira & Informático \\
\hline Sigrid Solano Moraga & Filóloga \\
\hline Jacobo Shifter & Historiador \\
\hline Lelia Villalobos Rodríguez & Profesora de inglés \\
\hline Aracelly Ugalde Víquez & Bibliotecóloga \\
\hline Jessie Campos Chacón & Bibliotecóloga \\
\hline Jorge Meneses & Bibliotecólogo \\
\hline Ana Barquero & Bibliotecóloga \\
\hline Oledys Ramírez & Bibliotecóloga \\
\hline
\end{tabular}

Fuente: Elaboración propia de las autoras. 
El trabajo realizado en años anteriores ha permitido adquirir una mayor experiencia en cuanto a conocimientos y destrezas en un campo que era desconocido en nuestra universidad cuando se inició en esta Facultad. Sin embargo, todavía falta recuperar muchos trabajos realizados en años anteriores, al mismo tiempo que se recopila el trabajo que se va produciendo en estos momentos.

A nivel mundial las bibliotecas se organizan según el usuario que se atiende, la institución en la que está inmersa y la tecnología que utiliza: biblioteca nacional, bibliotecas públicas, escolares, universitarias y especializadas, entre otras; todas estas de tipo tradicional o en la red. Poseen distintas funciones y cumplen una misión diversa en el ámbito público o el privado. La Universidad Nacional posee un sistema documental que reúne las bibliotecas de sus facultades, centros y sedes (SIDUNA) y un repositorio institucional que fue instalado en el año 2014. Es en este repositorio en donde está ubicada la colección de la Biblioteca Scriptorium como la primera comunidad que aportó documentación organizada.

La base del diseño y fundamentación de esa biblioteca es la Tecnología de la Información y de la Comunicación (TIC) y la creatividad. Esas innovaciones tecnológicas permiten ofrecer servicios novedosos para facilitar el acceso y la respuesta inmediata ante las necesidades de sus usuarios. Según Faba y Nuño (2004) de acuerdo con el uso de las TIC, se distinguen los siguientes tipos de bibliotecas:

a) Biblioteca digital: "Es un servicio de información/biblioteca localizado en un espacio, ya sea virtual o físico, o en una combinación de ambos, en el que una proporción significativa de fuentes disponibles para el usuario existe solo en forma digital" (Bawden y Rowlands, 1999, p.6). Es un repositorio de acervos y contenidos digitalizados, almacenados en diferentes formatos electrónicos por lo que el original en papel, en caso de existir, pierde supremacía. Generalmente, son bibliotecas pequeñas y especializadas, con colecciones limitadas a solo algunos temas (López Guzmán, 2000). Es aquella que contiene elementos digitalizados, es decir, contenidos completos de 
todo tipo, que incluso, a veces tienen una forma cambiante a causa de su constante actualización, que aplica la tecnología en cualquiera de sus formas, pero en la que no actúa el elemento humano de una manera directa y simultánea al servicio que da (Pérez, 2000).

Las bibliotecas digitales son bibliotecas electrónicas en las que un gran número de usuarios distribuidos geográficamente tienen acceso a una gran cantidad de contenidos diversos de objetos electrónicos (Yerkey y Jorgensin, 1996, citados por Sreenivasulu, 2000). La biblioteca digital o virtual puede considerarse meramente como un depósito de textos electrónicos en línea (Ince, 2001).

b) Biblioteca electrónica: es la que posee:

Sistemas de automatización que le permiten una ágil y correcta administración de los materiales que resguarda, principalmente en papel. Asimismo, posee sistemas de telecomunicaciones para consultar la información, en formato electrónico, de manera remota o local. Proporciona principalmente catálogos y listas de las colecciones que se encuentran físicamente dentro de un edificio (López, 2000).

Además, permite acceder a bancos de información en formato electrónico. Este tipo de bibliotecas incluiría también los catálogos automatizados de bibliotecas tradicionales. Según esta definición, la biblioteca electrónica intentaría reproducir la producción impresa, pero utilizando un medio diferente del soporte papel (Pérez, 2000).

c) Biblioteca híbrida: es un modelo de biblioteca en el que el usuario, desde un interface vía web o Windows y a través de páginas o pantallas, puede acceder a los recursos digitales, representados en siete bloques: (a) pasarela a internet; (b) fuentes primarias: revistas electrónicas, materiales digitalizados en el propio centro, literatura gris; (c) fuentes secundarias: bases de datos, CD-ROM; (d) catálogos: OPACS locales, catálogos de consorcios; (e) acceso a editoriales y librerías; (f) intermediarios 
comerciales: agentes de suscripción, host; (g) servicios de información en tiempo real: medios de comunicación (Oppenheim y Smithson, 1999). Es una biblioteca híbrida, también denominada pasarela que suministra un entorno y unos servicios parcialmente físicos y parcialmente virtuales (Bawden y Rowlands, 1999). Se halla entre la biblioteca convencional y la digital, donde las fuentes de información electrónicas e impresas se usan conjuntamente (Garrod, 2001).

d) Biblioteca virtual: esta expresión se utiliza para describir colecciones de recursos web (Bawden y Rowlands, 1999). Es aquella que utiliza la realidad virtual para mostrar una interfaz y emular un ambiente que sitúe al usuario dentro de una biblioteca tradicional. Usa la más alta tecnología multimedia y puede guiar al usuario a través de diferentes sistemas para encontrar colecciones en diferentes sitios, conectados a través de sistemas de cómputo y telecomunicaciones (López Guzmán, 2000).

Se trata de una biblioteca que ofrece un valor añadido a la biblioteca digital complementándola con servicios bibliotecarios y documentales, en los cuales interviene, de forma constante el elemento humano, que ayuda y complementa la acción del usuario, dándole estos servicios de forma virtual (a distancia), y que aprovecha la respuesta virtual de los usuarios para organizar la información y los contenidos que este necesita, o para darle las herramientas necesarias para obtener información (Pérez, 2000). Las bibliotecas virtuales son sistemas basados en la tecnología web que tienen alojadas numerosas bases de datos científicas, muchas de las cuales se hallan en texto completo (Fitzgerald y Galloway, 2001).

Por tanto, como el propósito de Scriptorium es consolidar una biblioteca digital de acuerdo con la definición anterior, cuenta con un repositorio de documentos que, en este caso, es de acceso gratuito o abierto a la comunidad universitaria y mundial. Un repositorio se define como el espacio electrónico que pretende "la difusión y el aumento del impacto entre la comunidad científica de los resultados de investigación" (Sánchez y Melero, 2006, p. 2). 
Ampliado por De Volder (2008) "los repositorios institucionales digitales reúnen la producción científica y/o académica de los miembros de una o varias instituciones resultado de su actividad docente e investigadora, almacenando, preservando, divulgando y dando acceso abierto a los recursos depositados en ellos" (p. 81).

En el campo de la edición, es necesario subrayar que los documentos que se reciben para los repositorios o bibliotecas electrónicas casi nunca cumplen con la calidad y los requisitos necesarios para integrarlos automáticamente a estas. Generalmente requieren un largo y detallado proceso de revisión y edición; esta tarea la lleva a cabo una filóloga. La corrección de estilo es el proceso de revisión del texto de acuerdo con ciertas normas aceptadas convencionalmente con el fin de que transmita las ideas de la forma más económica y logre el máximo de comprensión. En los repositorios se realiza un proceso de edición que promueve la gestión y la difusión de documentos mediante la publicación digital de los resultados de los programas, proyectos y actividades académicas de investigación, extensión y docencia.

\section{Metodología}

La totalidad del trabajo para lograr incorporar un documento a la red digital posee varias fases, cada una de las cuales está a cargo de diferentes profesionales. En general, cada documento debe recopilarse, procesarse e incorporarse tanto al catálogo de la biblioteca digital como a la red, para lo cual se requiere de un trabajo a cargo de filólogos, bibliotecólogos e informáticos. Por lo tanto, la participación de un equipo interdisciplinario es muy enriquecedora por la sinergia que surge a partir de la interacción profesional permanente mediante la cual se discuten los problemas y los procedimientos para superarlos conjuntamente.

El objeto de estudio es la producción académica de la Facultad de Filosofía y Letras en sus diferentes modalidades y formatos. Para llevar a cabo este cometido, se requiere una metodología de investigación exploratoria con el fin de identificar, determinar y establecer los 
elementos constitutivos y los procesos de construcción de los espacios de comunicación y también para la búsqueda, la identificación y la selección del material que constituye el repositorio. Se emplea, además, la investigación bibliográfica documental como complemento de la búsqueda y la identificación de las publicaciones. Forma parte de esa investigación el control documental institucional, nacional e internacional con el propósito de ubicar las actividades y los documentos ya que los autores publican no solo en fuentes universitarias nacionales.

De cada publicación se llevan a cabo varios análisis: documental, editorial y filológico; y se revisa que la calidad sea la óptima para poder subir el documento a la web; además, se cataloga e ingresa cada documento en la base de datos institucional ubicada en el SIDUNA.

Se utiliza el análisis de sistemas para la selección de los instrumentos tecnológicos apropiados para el resguardo, el mantenimiento y la administración de la biblioteca electrónica, por ejemplo, en la elaboración de las bases de datos, los catálogos y el boletín informativo. Para lograr la meta que se pretende tener -una cobertura total de la producción y las actividades académicas que realiza la facultad- esos métodos no son suficientes; por lo tanto, el control documental constituye la actividad más exigente del proyecto, justifica su carácter permanente y obliga a la búsqueda de metodologías innovadoras.

A su vez, todo lo anterior también implica la participación en comisiones institucionales con el fin de definir los parámetros necesarios.

\section{a) Etapa I: Recopilación de documentos}

En esta etapa se elaboraron investigaciones bibliográficas en la Universidad Nacional y en general en Costa Rica para identificar las fuentes de información que referencien la producción intelectual, algunas de las cuales se reseñan en documentos del archivo institucional. En el caso de este repositorio, los criterios de selección son muy sencillos: se trata de recuperar todas las publicaciones académicas originales de la Facultad de Filosofía y 
Letras desde su fundación. En esta etapa no se juzgó el valor patrimonial del material bibliográfico ni su estado de conservación, tampoco su mayor o menor demanda de uso.

A partir de esa información se llevó a cabo una investigación exploratoria para identificar a los autores intelectuales de la producción intelectual que se contactan una vez informados del proyecto y motivados a colaborar con la difusión de la información. Por medio de consultas, lectura y comentarios persona a persona, se identifican los insumos del repositorio y se motivó su participación.

Los documentos identificados estaban en diversos materiales o lenguajes; cada uno es objeto de la edición respectiva y su análisis documental antes de ingresarlo al repositorio. Se realizaron varias depuraciones. Con respecto a los derechos de autor, se respetó la ley vigente.

\section{b) Etapa B: Digitalización}

Los documentos se encontraron en dos formatos: impresos o digitales. En caso de que los documentos impresos no cumplan con las normas establecidas en el proyecto, deben de seguir una serie de pasos para poder pasar a la etapa de edición. El proceso de los documentos impresos incluye varias etapas: escaneo, digitalización, edición y conversión a PDF. Para esto, se requieren diversas herramientas tecnológicas como procesador de textos, programas de creación de edición de documentos, captura, diseño y digitalización de imágenes. El tratamiento dado a la imagen digital tiene que ver con la calidad en cuanto a sus cualidades estéticas y con sus características de archivo de información. Para esta etapa es fundamental contar con el software necesario para la digitalización de las imágenes y otros documentos.

Durante el proceso de selección de salidas se garantiza la calidad de la digitalización después del escaneo de los documentos. En esta etapa se completa el ciclo de las imágenes, se define el almacenaje o archivo, la obtención de impresiones digitales y la circulación y el intercambio. 
La edición del documento consiste en la revisión total y detallada de los contenidos. En primer lugar, se verificó que el documento tenga calidad académica original, lo cual implicó comprobar que efectivamente haya sido una publicación del autor y en la fuente indicada, sea revista o editorial. En segundo lugar, el documento que pasa se revisa con las tradicionales normas filológicas y el sistema MLA. Se agregó una nota al pie de página con los datos de publicación de cada documento cuando no la tengan.

Todos los documentos, una vez editados y convertidos a PDF, deben ser catalogados para su posterior publicación; para esto se requiere el permiso de utilización del sistema Aleph. Una vez indizado y descrito se puede publicar electrónicamente en la página respectiva, de acuerdo con el mapa conceptual previamente diseñado para todo el repositorio.

\section{c) Etapa C: Evaluación y divulgación}

Se realizó una evaluación permanente de los sitios donde se coloquen los documentos digitales, sea el OPAC del SIDUNA o el repositorio. Además, para la redacción del informe parcial cada año se llevó a cabo una evaluación global. Con los resultados de las evaluaciones se hace el respectivo mantenimiento siempre con la meta de ofrecer un espacio novedoso, pertinente y útil para la comunidad universitaria.

Respecto a la difusión, se utilizan los mini sitios y las redes sociales. Para estos se hacen sinopsis de cada publicación, a la que se agrega una o varias imágenes. Las sinopsis consisten en una síntesis del contenido a la que se agrega una valoración que llame la atención del lector. Se indica la dirección URL para que este entre directamente al sitio de la publicación.

En el área de las tecnologías informáticas se usaron tres herramientas para la elaboración de sitios web, el repositorio y el catálogos en línea: Joomla, Dspace y Aleph. La primera debido a que son los sistemas que se utilizan en los de los sitios web de la UNA; Aleph es un complejo programa integrado por varios módulos con el que se maneja el Sistema de bibliotecas de la 
UNA. Posee un módulo específicamente diseñado para la catalogación que es el principal de la base de datos del repositorio de la facultad.

\section{Logros y desafíos}

A la fecha -inicios de 2017-, la Biblioteca contiene a su haber 1.959 documentos ubicados en el sistema documental de la Universidad; se dispone de todos los trabajos finales de graduación y se suma la digitalización con todos los números de 40 años, que origina 1.170 registros, desde 1919 a 1959, de la más importante revista costarricense de todos los tiempos: Repertorio Americano (http://www.repositorio.una.ac.cr).

Esta colección abarca también publicaciones inéditas que fueron el resultado de cinco investigaciones, o sea, publicadas únicamente en esta Biblioteca. Estas se pueden consultar en el sitio y en el SIDUNA y son tres documentos históricos:

1. Aguilar, Alma R. y Tomcsányi, Judit. (2015). De la Idea a la palabra. Adquisición de la temporalidad y las estructuras textuales en lengua extranjera.

2. Duncan, Quince. (2014), Una memoria de los primeros años de la Universidad Nacional.

3. Núñez, Benjamín (2016), Discursos, recopilación de Diana Rojas Mejías y Ignacio Coto Cedeño, edición de Scriptorium.

4. Pérez Miguel, Rafael. (2012). Exploración bibliográfica sobre el cuento erudito costarricense.

5. Rojas González, Margarita (2013). Lectura sucinta de las páginas fundadoras de la Universidad Nacional 1973-2013.

6. Se dispone también de los primeros Planes de estudio del Departamento de Filosofía.

Aprovechando la tecnología se han realizado varios mini sitios, antecedidos por dos exposiciones digitales: Carlos Santander (obra literaria y ensayística), Mapas del límite fronterizo Costa Rica-Nicaragua; Yolanda Oreamuno; Mujeres en el Repertorio Americano. Casi todas recuperaron materiales inéditos, producidos por varios académicos de la FFL, tesis 
que estaban inéditas, fotografías provistas por familiares, y también se generaron, por ejemplo, 61 biografías originales de mujeres que escribieron en Repertorio Americano. Para ahondar en conflictos y opiniones, se preparó un mini sitio con artículos de académicos de la Facultad, titulado Cocorí: ¿Hay racismo en "Cocorí"? (http://issuu.com/carolinagomezfernandez/docs/cocori achacong)

Además, se identificaron todos los trabajos finales de graduación elaborados por los estudiantes de la Facultad desde 1973 hasta el 2015. Los más antiguos que están en formato únicamente impreso están por terminar el proceso de digitalización y publicación como una de las prioridades en Scriptorium. Paralelamente, se elaboró un catálogo que incluyó 43 años de estos documentos y paralelamente.

Se han publicado, anualmente, catálogos de programas, proyectos y actividades académicas realizadas en la Facultad de Filosofía y Letras desde el año 1997. Los últimos cinco años se publicaron también en formato digital para que el personal académico y el estudiantado tuvieran acceso a esta información que no está disponible en ninguna otra instancia universitaria. Los datos sobre el Premio Omar Dengo y el Certamen Una Palabra se recopilaron, incluyendo los datos de la comisión organizadora, evaluadores y autores premiados.

En 2006 se publicó por primera vez en la Universidad Nacional el catálogo "35 años de producción académica" y en 2013 se complementó mediante la publicación de un nuevo catálogo para celebrar los 40 años con la identificación de 1.394 registros. Para finales de 2016, se habían ingresado al repositorio institucional 52 ponencias presentadas en las actividades académicas nacionales e internacionales, entre ellas:

- 11 en el CIESUP

- 5 en el Congreso internacional de literatura centroamericana (CILCA)

- 5 en el Coloquio de ética y desarrollo

- 2 en el Congreso Universo de las revistas 
Bibliotecas. Vol 36, № 2, enero - junio, 2018. EISSN: 1659-3286

URL: http://www.revistas.una.ac.cr/index.php/bibliotecas/index

- 1 en el ISRI 2010

- 5 en el Jornadas andinas de literatura (Jalla) 2006

- 2 en el Metáforas de la sociedad

- 3 en Pensadores humanistas

- 1 en el Seminario de Bibliotecología

- 2 en el VI Congreso de humanidades

- 15 en el VII Congreso internacional de estudios latinoamericanos

La Facultad de Filosofía y Letras es una de las facultades fundadoras de la Universidad Nacional. En sus orígenes fue la instancia, casi única, encargada del desarrollo de las áreas humanísticas de nuestra casa de estudios, pues era también el espacio para el cultivo de las áreas de letras, arte, tecnología, deportes y educación, mientras que se crearon los centros especializados en estos campos, previstos desde el primer Estatuto Orgánico. Siendo una de las facultades que más produce documentos en la Universidad Nacional, lleva a cabo una labor pionera en la construcción de repositorios a nivel nacional y, dentro de la institución, ha participado activamente en la toma de decisiones para la construcción del repositorio institucional.

Esta biblioteca se consolidó como el laboratorio de práctica del estudiantado de la Universidad Nacional, donde la biblioteca es siempre un diseño creativo y una novedad junto con la historia, la cultura, la investigación, el descubrimiento y la lectura, que son una compañía inseparable que disfrutan los participantes. La colaboración y el aprendizaje que se da entre profesores y estudiantes, el esfuerzo, la revisión constante, la práctica metódica y el interés marcan una diferencia enorme, caracterizada por el nivel de compromiso, de entusiasmo, de creatividad y por el amor que mostraron ante su aporte, más allá del deber y de lo esperado.

Los aportes estudiantiles son atesorados como logros profesionales y se pueden observar al visitar los sitios electrónicos y las redes sociales. Destacamos especialmente la participación de estudiantes de las diferentes escuelas de nuestra Facultad, pero también de las facultades 
de educación y ciencias exactas. Sobresale la participación de estudiantes de informática, de literatura, de filosofía y, por supuesto, grupos completos de la Escuela de Bibliotecología, Documentación e Información que junto con sus profesores exploraron las nuevas fronteras al elaborar insumos para los servicios de información en línea. Además, la participación de los estudiantes se registró en el Sistema Académico de la Universidad y tiene constancia en sus expedientes para el futuro currículo profesional de los todos los participantes.

Se recomienda mantener el aporte que ofrece la Facultad a la investigación y la docencia porque constituye un gran logro que se pudo realizar mediante el trabajo interdisciplinario, en equipo y del deseo de ofrecer información y servicios novedosos aprovechando al máximo la tecnología disponible. Corresponde continuar con este esfuerzo adecuando los servicios y características creativamente, mantener colecciones actualizadas y ampliar servicios audiovisuales que incluyan conferencias, defensas de trabajos finales de graduación, televisión y radio sobre las letras y la filosofía costarricense.

La Escuela de Bibliotecología, Documentación e Información deberá promover esta biblioteca como un modelo de trabajo interdisciplinario, en equipo, con un seminario permanente de investigación y de implementación de las prácticas más novedosas y aprovechar el espacio para ofrecer cursos sobre la teoría y su puesta en práctica.

\section{Referencias bibliográficas}

Bawden y Rowlands, (1999). Digital Libraries: assumptions and concepts. Libri, vol. 49. En https://pdfs.semanticscholar.org/acdc/6bd339e3ac81558dee63fb5059de1e4699fb.pdf

De Volder, C. (2008). Los repositorios de acceso abierto en la Argentina: Situación actual. Información. Cultura y Sociedad, 19.

Faba, C. y Nuño, M. (2004). La nueva gestión en las bibliotecas virtuales. Boletín de la Asociación Andaluza de Bibliotecarios, 74, En: http://eprints.rclis.org/6202/1/74a2.pdf

Facultad de Filosofía y Letras. (2016). Biblioteca Electrónica Scriptorium. Disponible en http://www.scriptorium.una.ac.cr 
Fitzgerald, M. y Galloway, C. (2001). Relevance judging, evaluation, and decision making in virtual libraries: a descriptive study. Journal of the Association for Information Science and Technology, $52 \quad$ (12), Disponible en http://onlinelibrary.wiley.com/doi/10.1002/asi.1152/abstract

INCE, D. (2001). A dictionary of the Internet. Oxford: University Press.

López, C. (2000). Modelo para el desarrollo de bibliotecas digitales especializadas. México: C. López Guzmán.

Manso, A. (2015). La biblioteca y sus ofertas: reflexiones a partir del desarrollo tecnológico actual. Ciencias de la información, 46 (3).

Pérez, D. (2000). La biblioteca digital. Disponible en http://www.uoc.edu/web/esp/articles/La biblioteca digital.htm

Rojas, M. (2012). Scriptorium: una biblioteca necesaria, en Suplemento cultural, Universidad Nacional, $105 . \quad$ Disponible en http://www.icat.una.ac.cr/suplemento cultural/index.php/features/292-margaritarojas-g/1056-scriptorium-una-biblioteca-necesaria-margarita-rojas-g-suplemento-105

Sánchez, S y Melero, R. (2006). La denominación y el contenido de los repositorios institucionales en Acceso Abierto: base teórica para la "Ruta Verde". Disponible en: http://eprints.rclis.org/7613/1/Denominaci\%C3\%B3n contenido OA.pdf

Sreenivasulu, V. (2000). The role of a digital librarian in the management of digital information systems (DIS). The Electronic Library, 18 (1). Disponible en https://doi.org/10.1108/02640470010320380

\section{Notas de las autoras}

* Aracelly Ugalde Víquez: académica de la Escuela de Bibliotecología, Documentación e Información. Universidad Nacional. Correo electrónico: aracelly.ugalde.viquez@una.cr.

** Margarita Rojas González: investigadora de literatura latinoamericana y profesora de teoría literaria y semiótica. Escuela de Literatura y Ciencias del Lenguaje, Universidad Nacional. Correo electrónico: margarita.rojas.gonzalez@una.cr.

*** Carolina Gómez Fernández: soporte informático en la Facultad de Filosofía y Letras, Universidad Nacional. Correo electrónico: carolina.gomez.fernandez@una.cr. 